\title{
KARAKTERISASI DAN KLASIFIKASI TANAH ULTISOL DI KECAMATAN INDRAJAYA KABUPATEN PIDIE
}

\author{
Sri Handayani ${ }^{1}$, Karnilawati ${ }^{2}$ \\ ${ }^{1}$ Staf Pengajar Fakultas Pertanian, Universitas Jabal Ghafur, Gle Gapui Sigli \\ E-mail : s.handayani2000@gmail.com \\ ${ }^{2}$ Staf Pengajar Fakultas Pertanian, Universitas Jabal Ghafur, Gle Gapui Sigli \\ E-mail : ksdl_niela@yahoo.co.id
}

\begin{abstract}
This study aims to examine the characteristics of Ultisol soil and produce a system of naming Ultisol soil according to the USDA Land Taxonomy system in Indrajaya District, Pidie District. This research will be carried out in the villages of Gle Gapui, Tuha Suwiek and Masjid Suwiek Indrajaya sub-districts from June to November 2015. This study uses descriptive-quantitative method, which consists of the following stages: (1) Preparation, ie collecting secondary data such as climate data, maps etc. Then prepare the tools and materials for the field survey and establish the ground pedon (2) Field activities, including observation of soil profile, soil sampling, laboratory analysis. Subsequently classified the land based on the USDA Land Taxonomy System

Profile Gle Gapui climber determinant (horate Bt) textured clay where there is increasing clay so it is included into the horizontal horizon. Content weight value is inversely proportional to permeability and porosity. The soil reaction is directly proportional to the saturation of base which is equally low. The content of $\mathrm{C}$ - organic, $\mathrm{P}$ is available and $\mathrm{N}$ total is low. Moderate Cation Exchange Capacity, exchangeable acids ( $\mathrm{H}$ and $\mathrm{Al})$ are high.

The classification of Ultisol soil in the location of the Glealing Glean profile is Typic Hapludult, berliat, blend, isohipertermik.

Keywords: characteristic, classification, ultisol soil,
\end{abstract}

\section{PENDAHULUAN}

Pembentukan tanah dipengaruhi oleh lima faktor yang berkerja sama dalam berbagai proses, baik secara fisik maupun kimia. Di Indoesia ada bermacam-macam jenis tanah dimana tanah tersebut memiliki sifat dan cirinya masing-masing yang merupakan pembeda antara satu tanah dengan yang lainnya. Salah satunya adalah tanah Podsolik Merah Kuning (PMK), yang sering disebut sebagai tanah - tanah bermasalah atau tanah marginal. Tanah-tanah ini relatif kurang subur, kandungan unsur haranya rendah dan bereaksi masam.

Kendala Ultisol (PMK) baik ditinjau dari segi fisika, kimia dan biologi tanah, seperti : bahan organik rendah sampai sedang, kemasaman
Aldd tinggi, kandunga unsur hara , N, P, K rendah, Nilai KTK dan KB rendah dan sangat peka erosi. Walaupun tanah ultisol ini mempunyai sifat kimia yang kurang baik, tetapi jika dilakukan pengelolaan tanah yang sesuai bisa berproduksi secara optimal. Semestinya data maupun informasi tentang sifat tanah ini harus diketahui, sehingga dalam pemanfaatannya bisa memperbaiki dan meningkatkan kondisi tanah tersebut. Saat ini karena tanah-tanah yang relatif subur semakin berkurang akibat penggunan lahan yang tidak sesuai, maka pemerintah terpaksa mulai memanfaatkan tanah-tanah yang relatif kurang subur seperti Ultisol untuk memenuhi kebutuhan hidup masyarakat. 
Dalam perbaikan tanah Ultisol ini perlu diperhatikan cara - cara pengelolaan yang baik sehingga tanah menjadi produktif dan tidak rusak. Sistem pengklasifikasian tanah Ultisol merupakan pegangan/panduan bagi pengguna tanah maupun pengelola tanah dalam melakukan perbaikan sifat tanah Ultisol ini. Pada pengklasifikasian ini akan dilihat sifat morfologi, kimia dan fisika yang merupakan karakteristik dari suatu jenis tanah.

Menurut Hardjowigeno (2010) klasifikasi tanah adalah usaha untuk membeda-bedakan tanah berdasarkan atas sifat - sifat yang dimilikinya. Dengan cara ini maka tanah-tanah dengan sifat yang sama dimasukan ke dalam satu kelas yang sama. Hal ini penting karena tanah-tanah dengan sifat yang berbeda memerlukan perlakuan (pengelolaan) yang berbeda pula.

Sistem klasifikasi tanah pada akhirnya akan menghasilkan tata nama (penamaan) dari suatu jenis tanah. Dari tata nama tersebut bisa diketahui sifat dan ciri tanah tersebut.

Berdasarkan uraian diatas peneliti merasa perlu melakukan penelitian ini, disamping penelitian mengenai klasifikasi tanah Ultisol di daerah penelitian belum pernah dilakukan.

\section{METODE PENELITIAN}

Tempat dan Waktu Penelitian

Penelitian ini dilaksanakan di desa Gle Gapui yang merupakan lokasi kampus Universitas Jabal Ghafur Sigli, Tuha Suwiek dan Mesjid Suwiek Kecamatan Indrajaya Kabupaten Pidie. Analisis tanah dilaksanakan di Laboratorium Kimia Tanah, Laboratorium Geologi, Mineralogi dan Klasifikasi Tanah serta Laboratorium Fisika Tanah dan Lingkungan Fakultas Pertanian Universitas Syiah Kuala. Penelitian ini akan dilaksanakan pada bulan Juli 2016.

Bahan dan Alat Penelitian

Bahan yang digunakan dalam penelitian ini adalah: peta administrasi , peta titik pengamatan , peta lereng, peta ketinggian tempat dan peta jenis tanah Kecamatan Indrajaya Kabupaten Pidie, serta sampel tanah dan bahan-bahan larutan seperti $\mathrm{H} 2 \mathrm{O} 210 \%$ dan larutan $\mathrm{HCl} 0,1 \mathrm{~N}$.
Alat yang digunakan dalam penelitian ini yaitu: GPS (global positioning system), kantong plastik, karet, ring sample, kartu deskripsi profil tanah, buku Munsell soil colour chart, meteran, kamera digital, cangkul, sekop, bor tanah, pisau tanah, alat tulis dan alat pendukung lainnya.

\section{Metode Penelitian}

Metode yang digunakan dalam penelitian ini adalah metode deskriptif-kuantitatif (terukur) dengan melakukan pengamatan di lapangan. Kemudian ditentukan titik pembuatan pedon untuk dilakukan pengamatan lebih lanjut, seperti pengambilan sampel tanah dan di lanjutkan dengan analisis laboratorium. Penetapan pedon yang akan diamati berdasarkan perbedaan kemiringan lereng Dalam mengklasifikasikan suatu jenis tanah, tanah diklasifikasikan terlebih dahulu ke dalam kategori ordo, kemudian ditentukan subordo, great group, sampai famili. Tanah diklasifikasikan dengan memisahkan masing-masing golongan

Tahapan pelaksanaan penelitian adalah :

\section{Persiapan .}

Sebelum turun ke lapangan dilakukan pengumpulan data-data skunder yang berasal dari instansi pemerintah yang terkait dengan penelitian ini seperti data iklim, peta dan informasi lain yang berhubungan dengan kondisi wilayah penelitian.

\section{Kegiatan Lapangan}

Tahap awal pelaksanaan kegiatan di lapangan adalah dengan melakukan penentuan titik pengamatan dengan pengeboran pada kemiringan yang berbeda, kemudian ditentukan titik pedon yang akan diamati. Pengambilan titik koordinat untuk menentukan posisi titik profil dengan menggunakan GPS. Pada setiap profil tanah diamati sifat morfologi, kimia dan fisik tanah.

Tahapan kegiatan di lapangan sebagai berikut :

1. Pengamatan profil tanah

Pengamatan dimulai dengan mengukur dalamnya profil, diukur dari lapisan atas sampai bawah.Penarikan batas horison atau lapisan tanah ditentukan dengan melihat perbedaan warna atau perbedaan padatan. Perbedaan padatan ditentukan 
dengan cara menusukkan pisau ke dalam tanah dengan tekanan tetap kemudian dilakukan penetapan batas horison dan pencatatan kedalamannya pada daftar isian profil. Pengamatan profil tanah dilakukan untuk mendapatkan data sifat-sifat morfologi tanah secara lengkap (Tabel 1). Karakteristik morfologi lahan lainnya yang diamati seperti kelerengan, drainase permukaan, vegetasi, batuan permukaan dan sebagainya.

Tabel 1.Sifat Morfologi, fisika dan kimia tanah di lapangan

\begin{tabular}{|c|c|}
\hline $\begin{array}{l}\text { Sifat-sifat yang } \\
\text { diteliti }\end{array}$ & Metode Pengamatan/Alat \\
\hline Fisiografi & Melihat bentuk lahan daratan \\
\hline Vegetasi & Pengamatan di lapangan \\
\hline $\begin{array}{l}\text { Ketinggian } \\
\text { tempat }\end{array}$ & GPS \\
\hline Tekstur tanah & $\begin{array}{l}\text { Pemijatan tanah ( ibu jari } \\
\text { dengan telunjuk) }\end{array}$ \\
\hline Struktur tanah & Pengamatan agregat \\
\hline Warna Tanah & $\begin{array}{l}\text { Buku Munsell Soil Colour } \\
\text { Chart }\end{array}$ \\
\hline Konsistensi tanah & $\begin{array}{l}\text { Menekan tanah dengan ibu } \\
\text { jari dan telunjuk }\end{array}$ \\
\hline pH lapangan & pH tancap \\
\hline Bahan organic & Larutan $\mathrm{H} 2 \mathrm{O} 210 \%$ \\
\hline Kandungan kapur & Larutan $\mathrm{HCl}$ \\
\hline Solum & Pemboran tanah \\
\hline $\begin{array}{l}\text { Drainase dalam } \\
\text { dan luar }\end{array}$ & $\begin{array}{l}\text { Aliran air permukaan dan air } \\
\text { yang masuk kedalam tanah }\end{array}$ \\
\hline
\end{tabular}

2. Tehnik pengambilan sampel tanah

Pengambilan sampel tanah dilakukan pada setiap titik pengamatan dan pembersihan tebing sebagai pedon yang akan diamati dan sampel tanah diambil pada setiap lapisan/horison. Contoh pengambilan tanah dilakukan dua cara yaitu: (1) contoh tanah tidak terganggu (ring sampel) untuk penetapan sifat fisika tanah dan (2) contoh tanah terganggu untuk penetapan sifat kimia tanah

3. Analisis tanah di laboratorium

Untuk keperluan analisis sifat fisika dan kimia tanah di laboratorium, contoh tanah terganggu dikering-anginkan selama 1 minggu sampai tanah benar-benar kering, kemudian ditumbuk dan diayak dengan ayakan $2 \mathrm{~mm}$ sebelum dianalisis. Sedangkan contoh tanah pada ring sample dapat langsung dianalisis. Analisis sifat fisik, kimia dan mineral dapat dilihat pada Tabel 2

Tabel 2.Analisis fisika, kimia dan jenis mineral liat di laboratorium

\begin{tabular}{|c|c|}
\hline Aspek analisis & Metode/Alat \\
\hline Tekstur 3 fraksi & Pipet (Hukum Stokes) \\
\hline Permeabilitas & Permeameter \\
\hline Kadar Air pada & Pressure plate \\
\hline kapasitas lapang & apparatus \\
\hline Bobot Isi & Ring sampel \\
\hline Porositas & Ring sampel \\
\hline $\mathrm{pH} \mathrm{H} 2 \mathrm{O}$ dan $\mathrm{KCl}$ & Elektrometrik \\
\hline $\begin{array}{l}\text { Kadar Air kering } \\
\text { mutlak }\end{array}$ & Kering Oven (105 C) \\
\hline C-organik & Walkley dan Black \\
\hline $\begin{array}{l}\text { Kation basa dd } \\
(\mathrm{Na}, \mathrm{Ca}, \mathrm{Mg} \mathrm{K})\end{array}$ & $1 \mathrm{~N} \mathrm{NH4OAC} \mathrm{pH} 7$ \\
\hline $\begin{array}{l}\text { Asam-asam dd (Al, } \\
\mathrm{H})\end{array}$ & Ekstraksi $1 \mathrm{~N} \mathrm{KCl}$ \\
\hline $\begin{array}{l}\text { Extractable acidity } \\
\text { (EA) }\end{array}$ & BaCl2- TEA pH 8,2 \\
\hline KTK Tanah & $1 \mathrm{~N} \mathrm{NH} 4 \mathrm{OAC} \mathrm{pH} 7$ \\
\hline $\begin{array}{l}\text { Kejenuhan basa } \\
(\mathrm{KB})\end{array}$ & $\mathrm{KB}=\frac{\sum \text { basa }- \text { basa dd }}{\mathrm{KTK}} \times 100 \%$ \\
\hline KB jumlah kation & KB junlall kationl $=\frac{\text { Ebassa-basa dd }}{\sum \text { bassa-basa dd }+ \text { EA }}$ \\
\hline \multirow[t]{2}{*}{ KTK liat } & KTKlint - KTKNH4OAc-n. C-organik \\
\hline & $\%$ liat \\
\hline KTK jumlah kation & $\begin{array}{l}\Sigma \text { basa-basa dd } \\
(\mathrm{NH} 4 \mathrm{OAC} \mathrm{pH} 7)+\mathrm{EA}\end{array}$ \\
\hline Jenis mineral & $\begin{array}{l}\text { Didekati dari nilai KTK } \\
\text { liat }\end{array}$ \\
\hline
\end{tabular}

4. Klasifikasi tanah

Setelah diperoleh data-data dari lapangan dan hasil analisis laboratorium, dilanjutkan dengan klasifikasi berdasarkan "Keys to Soil Taxonomy" USDA tahun 2010. Penamaan tanah dilakukan mulai dari kategori ordo, subordo, great group, subgrup dan famili tanah. 


\section{HASIL DAN PEMBAHASAN}

Berdasarkan hasil pengamatan dilapangan dan analisis laboratorium bahwa jenis tanah pada lokasi profil Mesjid Suwiek dan Tuha Suwiek bukan jenis tanah Ultisol, sehingga pembahasan hanya pada profil Gle Gapui. Lokasi penelitian terletak pada N $05^{\circ} 16,19^{\circ}$ dan E $095^{\circ} 55^{\prime} 294^{\prime \prime}$, profil tanah dibuat di Desa Glee Gapui Kecamatan Indra Jaya Kabupaten Pidie.

\section{Karakteristik Morfologi dan Fisika Tanah}

Berdasarkan hasil pengamatan di lapangan dan hasil analisis laboratorium, karakteristik morfologi dan fisika tanah di daerah penelitian dapat dilihat pada Tabel 3.

Tabel 3. Nilai Sifat morfologi dan fisika profil tanah dilokasi profil Ultisol

\begin{tabular}{|c|c|c|c|c|c|c|c|c|c|}
\hline $\begin{array}{l}\text { Horizon/ } \\
\text { kedalaman } \\
(\mathrm{cm})\end{array}$ & Warna & Pasir & Debu & Liat & $\begin{array}{l}\text { Kelas } \\
\text { Tekstur }\end{array}$ & $\begin{array}{l}\text { Bobot isi } \\
(\mathrm{g} / \mathrm{cm} 3)\end{array}$ & $\begin{array}{c}\text { Permeab } \\
\text { ilitas } \\
(\mathrm{cm} / \mathrm{jam})\end{array}$ & Porositas & $\begin{array}{c}\text { Kadar } \\
\text { Air }\end{array}$ \\
\hline & & & $\%$ & & & & & \multicolumn{2}{|c|}{$\%$} \\
\hline Ap (0-7) & 10 YR 5/8 & 47 & 34 & 19 & Lempung & - & - & - & - \\
\hline $\mathrm{AB}(7-20)$ & 10 YR $6 / 8$ & 54 & 41 & 5 & $\begin{array}{l}\text { Lempung } \\
\text { Berpasir }\end{array}$ & 1,68 & 1,65 & 50,88 & 36,02 \\
\hline Bt1 (20-73) & 7,5 YR 5/3 & 10 & 37 & 53 & Liat & 1,61 & 0,32 & 44,13 & 27,60 \\
\hline Bt2 (73-90) & 7,5 YR $8 / 3$ & 17 & 7 & 78 & Liat & 1,75 & 0,45 & 35,73 & 25,04 \\
\hline BC $(90-150)$ & 10 YR 8/3 & 16 & 26 & 58 & Liat & - & - & - & - \\
\hline
\end{tabular}

Keterangan: 10 YR5/8 = kuning kecoklatan; 10 YR 6/8 = coklat kekuningan; 7,5 YR 5/3 = coklat terang ; 7,5 YR $8 / 3=$ orange kuning terang $; 10$ YR $8 / 3=$ orange kuning terang

\section{Warna Tanah}

Warna tanah merupakan petunjuk untuk beberapa sifat tanah, karena warna tanah dipengaruhi oleh beberapa faktor yang terdapat dalam tanah tersebut. Warna tanah ditentukan dengan menggunakan warna-warna baku yang terdapat dalam buku Munsell Soil Colour Chart.

Warna tanah di profil Gle Gapui pada horison Ap masuk ke dalam epipedon okhrik, walaupun mempunyai C-Organik 1,34\% (>0,6\%), tetapi mempunyai value lembab $5(>3)$, dan ketebalan horison Ap< $18 \mathrm{~cm}(7 \mathrm{~cm})$ sehingga tidak memenuhi syarat sebagai epipedon mollik.

\section{Tekstur Tanah}

Tekstur adalah perbandingan fraksi pasir, debu dan liat dalam massa tanah yang ditentukan di laboratorium. Pada profil Gle Gapui terjadi peningkatan jumlah liat pada penggal penentu/control section (horison $\mathrm{Bt} 1$ dan $\mathrm{Bt} 2$ sebagai horison penciri Ultisol) yaitu Bt1 $53 \%$ dan meningkat pada $\mathrm{Bt} 278 \%$ dibandingkan dengan horison diatasnya (AB) sebesar $5 \%$. Pada tingkat great group adalah Hapludult (Hapl = sederhana, horison berkembang minimum hanya 79 dibandingkan profil 3 Desa Glee Gapui Kecamatan Indara Jaya Kabupaten Pidie lebih berkembang setebal $90 \mathrm{~cm}$ )

\section{Bobot Isi, Permeabilitas dan Porositas Tanah}

Bobot isi sangat erat kaitannya dengan permeabilitas dan porositas, jika bobot isi tinggi maka permeabilitas dan porositas rendah dan sebaliknya jika permeabilitas dan porositas tinggi. Semakin tinggi bobot isi maka semakin padat tanah, sehingga semakin rendah permeabilitas tanah

Profil Gle gapui nilai bobot isi pada horison $\mathrm{Bt}\left(1.68\right.$, dan $\left.1.75 \mathrm{~g} / \mathrm{cm}^{3}\right)$ lebih tinggi dibanding horison $\mathrm{AB}$ diatasnya $\left(1.61 \mathrm{~g} / \mathrm{cm}^{3}\right)$, hal ini menunjukkan bahwa pada horison $\mathrm{Bt}$ tanah 
paling padat (penimbunan liat). Nilai permeabilitas berbanding terbalik dengan bobot isi, yaitu terjadi penurunan dari horison $\mathrm{AB}$ menuju Bt2 (1.65, 0.45 dan $0.32 \mathrm{~cm} / \mathrm{jam})$ dengan kriteria agak lambat - lambat, hal ini disebabkan makin padat tanah gerakan air menuju ke horison bawah makin lambat. Nilai porositas berkisar dari 44,13 - 35,73 \% (kriteria kurang baik - jelek) yang diisi oleh air dan udara $(<50 \%)$, sedangkan sekitar 55,87 - 64,27 \% diisi oleh bahan padat (mineral dan organik). dilokasi tersebut terjadi pemadatan tanah. Pemadatan tanah pada horison argilik $(\mathrm{Bt})$ yaitu horison penimbunan liat, merupakan lapisan penghambat perakaran, terutama untuk tanaman perkebunan yang mempunyai akar yang lebih dalam. Nilai kadar air pada kapasitas lapang $(\mathrm{pF}$ 2.54) pada profil $3(25,04-36,02 \%)$, hal ini sesuai dengan nama tanahnya pada tingkat subgrup adalah Typic Hapludult.

\section{Karakteristik Kimia Tanah}

Karakteristik kimia tanah di lokasi penelitian dapat dilihat pada Tabel 4

Tabel 4. Nilai sifat kimia profil dilokasi profil Ultisol udara sekitar 50\%, hal ini menunjukkan bahwa

\begin{tabular}{|c|c|c|c|c|c|c|c|c|c|c|c|c|c|}
\hline $\begin{array}{l}\text { Horizon/ke } \\
\text { dalaman } \\
(\mathrm{cm})\end{array}$ & $\begin{array}{l}\mathrm{pH} \\
\mathrm{H}_{2} \mathrm{O}\end{array}$ & $\begin{array}{l}\mathrm{pH} \\
\mathrm{KCl}\end{array}$ & $\begin{array}{l}\text { C- } \\
\text { Org } \\
(\%) \\
\end{array}$ & $\begin{array}{l}\mathrm{N}- \\
\text { total } \\
(\%)\end{array}$ & $\begin{array}{l}\text { P-av } \\
\text { (ppm } \\
\text { ) }\end{array}$ & $\mathrm{K}$ & $\mathrm{Na}$ & $\mathrm{Ca}$ & $\mathrm{Mg}$ & $\begin{array}{l}\mathrm{Hd} \\
\mathrm{d}\end{array}$ & $\begin{array}{l}\mathrm{Al} \\
\mathrm{dd}\end{array}$ & \multirow{2}{*}{$\begin{array}{l}\text { KTK } \\
\text { (me/ } \\
100 \mathrm{~g} \\
\text { ) }\end{array}$} & $\begin{array}{l}\mathrm{KB} \\
(\%)\end{array}$ \\
\hline & & & & & & \multicolumn{4}{|c|}{ Dapat ditukar (me/100 } & \multicolumn{2}{|c|}{$(\mathrm{me} / 100 \mathrm{~g})$} & & \\
\hline $\operatorname{Ap}(0-7)$ & 5,68 & 5,49 & $\begin{array}{l}1,3 \\
4\end{array}$ & 0,22 & 2,65 & $\begin{array}{l}2,8 \\
6\end{array}$ & $\begin{array}{l}0,2 \\
7\end{array}$ & $\begin{array}{l}4,0 \\
3\end{array}$ & 0,67 & $\begin{array}{l}0,1 \\
6\end{array}$ & ND & 10,80 & $\begin{array}{l}70 \\
37\end{array}$ \\
\hline $\mathrm{AB}(7-20)$ & 4,30 & 4,02 & $\begin{array}{l}0,6 \\
3\end{array}$ & 0,12 & 3,50 & $\begin{array}{l}0,1 \\
2\end{array}$ & $\begin{array}{l}0,2 \\
6\end{array}$ & $\begin{array}{l}1,0 \\
8\end{array}$ & 0,14 & $\begin{array}{l}0,4 \\
8\end{array}$ & 0,88 & 6,80 & $\begin{array}{l}23 \\
53\end{array}$ \\
\hline Bt1 (20-73) & 4,32 & 4,06 & $\begin{array}{l}0,7 \\
3\end{array}$ & 0,12 & 2,05 & $\begin{array}{l}0,3 \\
9\end{array}$ & $\begin{array}{l}0,3 \\
2\end{array}$ & $\begin{array}{l}0,5 \\
3\end{array}$ & 0,13 & $\begin{array}{l}2,1 \\
2\end{array}$ & 6,28 & 16,80 & $\begin{array}{l}8,1 \\
5\end{array}$ \\
\hline $\mathrm{Bt} 2(73-90)$ & 4,58 & 4,21 & $\begin{array}{l}0,5 \\
7\end{array}$ & 0,10 & 0,60 & $\begin{array}{l}0,3 \\
9\end{array}$ & $\begin{array}{l}0,3 \\
2\end{array}$ & $\begin{array}{l}0,1 \\
6\end{array}$ & 0,64 & $\begin{array}{l}3,4 \\
0\end{array}$ & 9,80 & 23,20 & $\begin{array}{l}6,5 \\
1\end{array}$ \\
\hline $\begin{array}{l}\mathrm{BC} \\
150)\end{array}$ & 4,55 & 4,32 & $\begin{array}{l}0,1 \\
7\end{array}$ & 0,09 & 0,70 & $\begin{array}{l}0,6 \\
1\end{array}$ & $\begin{array}{l}0,3 \\
3\end{array}$ & $\begin{array}{l}0,2 \\
9\end{array}$ & 0,66 & $\begin{array}{l}3,3 \\
6\end{array}$ & 10,40 & 24,80 & $\begin{array}{l}7,6 \\
2\end{array}$ \\
\hline
\end{tabular}

\section{Reaksi Tanah (pH tanah)}

Reaksi tanah menunjukan sifat kemasaman atau alkalinitas tanah yang dinyatakan dengan nilai $\mathrm{pH}$. Makin rendah nilai angkanya makin tinggi tingkat kemasamannya, dan makin tinggi nilai angkanya makin tinggi nilai alkalinitasnya. Tabel 3 menunjukan.

Pada lokasi penelitian pada penggal penentu (horison $\mathrm{Bt} 1$ dan $\mathrm{Bt} 2$ ) nilai $\mathrm{pH} \mathrm{H} 2 \mathrm{O}$ berkisar dari 4,32-4,58 (sangat masam - masam).
Nilai $\Delta \mathrm{pH}$-nya (selisih $\mathrm{pH} \mathrm{KCl}$ dengan $\mathrm{pH} \mathrm{H}_{2} \mathrm{O}$ ) 0.4 sampai -0.2. Tanah-tanah yang subur umumnya memperlihatkan antara nilai $\mathrm{pH} \mathrm{H}_{2} \mathrm{O}$ dan $\mathrm{pH} \mathrm{KCl}$ turun 1 satuan sehingga $\Delta \mathrm{pH}-1$ sehingga pada lokasi penelitian nilai $\Delta \mathrm{pH}$ muatannya hampir mendekati 0 (-0.4 sampai -0.4) (Tabel 3). Tabel 3 menunjukkan pada penentu (horison $\mathrm{Bt} 1$ dan dan $\mathrm{Bt} 2$ ) nilai $\mathrm{pH} \mathrm{H}_{2} \mathrm{O}$ berkisar dari 4,32-4,58 (sangat masam - masam). 


\section{Basa - basa Dapat Ditukarkan}

Kompleks pertukaran tanah selain ditempati kation-kation basa yang dikandungnya berkisar dari sangat rendah sampai sedang, dengan urutan sebagai berikut: Ca 0,16-0,53 $\mathrm{cmol} \mathrm{kg}^{-1}$ (sangat rendah), $\mathrm{Mg} 0,13-0,64 \mathrm{cmol} \mathrm{kg}^{-1}$ (sangat rendah - rendah), $\mathrm{K} 0,39 \mathrm{cmol} \mathrm{kg}^{-1}$ (sedang), dan $\mathrm{Na}$ 0,32 $\mathrm{cmol} \mathrm{kg}^{-1}$ (rendah) (Balai Penelitian tanah, Balitbangtan Deptan, 2005), komplek pertukaran tanah juga ditempati oleh kation asam dalam jumlah yang sangat banyak (tinggi - sangat

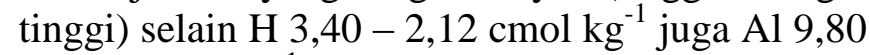
$-6,28 \mathrm{cmol} \mathrm{kg}^{-1}$ (komplek pertukaran dijenuhi $\mathrm{Al}$ 38 dan $42 \%$ ) yang dapat menganggu pertumbuhan dan meracuni tanaman (Hardjowogeno, 2003a). Nilai Kejenuhan Al diperoleh dari nilai Al-dd (Al dapat dipertukarkan) dibagi KTK dan dikalikan $100 \%$.

\section{Kapasitas Tukar Kation (KTK)}

Kandungan Kapasitas Tukar Kation (KTK) berkisar 23,20 - 16,80 cmol kg-1 (rendah sedang), sedangkan nilai pH-nya sangat masam masam, hal ini disebabkan pada kompleks jerapan tanah yang dijerap bukan hanya kation-kation basa juga kation-kation asam, sehingga mempunyai nilai KTK rendah - sedang. Pada penelitian ini tidak dilakukan analisis sifat mineralogi, untuk menentukan kelas mineralogi dapat didekati dari nilai KTK yaitu dijumpai mineral campuran (campuran mineral liat tipe $2: 1$ illit dan tipe $2: 1$ : 1 dengan KTK $10-40 \mathrm{cmol} \mathrm{kg}^{-1}$ ).

\section{Kejenuhan Basa (KB)}

Nilai Kejenuhan Basa (KB) berkisar 6,51 $-8,15 \%$ (rendah), hal ini sejalan dengan nilai $\mathrm{pH}$ tanah yang sangat masam - masam. Menurut Hardjowigeno (2003b) kejenuhan basa berhubungan erat dengan $\mathrm{pH}$ tanah, dimana tanahtanah dengan $\mathrm{pH}$ rendah mempunyai kejenuhan basa yang rendah.

\section{Kandungan C-Organik}

Kadar C-organik berkisar dari 0,57 - 0,73 $\%$ (sangat rendah), sedangkan pada lapisan top soil (horison A dan $\mathrm{AB}$ ) mempunyai C-organik
1,34 -0,63\% (rendah - sangat rendah), hai ini disebabkan pada lapisan atas dijumpai akar-akar tanaman dan rumput-rumputan yang melapuk dalam jumlah yang cukup banyak, sehingga mempengaruhi nilai C-organik.

\section{Nitrogen dan Fosfor}

Kandungan N sangat rendah - rendah $(0,09$ $-0,22 \%), P$ tersedia sangat rendah $(0,60-2,65$ $\mathrm{mg} \mathrm{kg}^{-1}$ ), hal ini sejalan dengan nilai C-organik. Sumber unsur hara nitrogen dan fosfor merupakan hasil dekomposisi dari bahan organik, selain itu hara-hara tersebut juga dapat berasal dari pelapukan batuan yang ada pada tanah tersebut (Hakim et al., 1986).

\subsection{Klasifikasi Tanah}

Berdasarkan hasil analisis tanah, karakteristik morfologi dan fisika profil tanah serta karakteristik kimia tanah di lokasi penelitian (Profil Gle Gapui), maka dapat diklasifikasikan seperti yang tertera pada Tabel 5 . 
Tabel 5. Klasifikasi tanah di lokasi penelitian (profil Gle Gapui)

\begin{tabular}{|c|c|c|c|}
\hline Penciri & $\begin{array}{l}\text { Nama } \\
\text { Penciri }\end{array}$ & $\begin{array}{l}\text { Uraian (Berdasarkan Data } \\
\text { Lapangan) }\end{array}$ & $\begin{array}{c}\text { Uraian (Berdasarkan Data } \\
\text { Laboratorium }\end{array}$ \\
\hline Epipedon & Okhrik & $\begin{array}{l}\text { Horison permukaan } \\
\text { berwarna terang dengan } \\
\text { value lembab }>0,6 \% \text {; atau } \\
\text { memenuhi syarat untuk } \\
\text { molik/umbrik kecuali } \\
\text { ketebalannya, atau kering } \\
\text { 3 bulan; atau } \\
\text { keras/sangat keras dan } \\
\text { masif bila kering }\end{array}$ & $\begin{array}{l}\text { Value lembab } 5(>3), \mathrm{C} \text { organik } \\
1,34(>0,6 \%) \text {, tetapi ketebalan } \\
\text { horizon Ap tanah }<18 \mathrm{~cm}(7 \mathrm{~cm}) \\
\text { tidak memenuhi sebagai } \\
\text { epipedon mollik, sehingga masuk } \\
\text { kedalam epipedon okhrik }\end{array}$ \\
\hline Horizon & Argilik & Horison penimbunan liat & $\begin{array}{l}\text { Pada horison AB liat } 5 \% \text { dan } \\
\text { terjadi kenaikan liat pada horison } \\
\text { Bt } 1 \text { dan Bt } 2 \text { berturut-turut } 53 \text { dan } \\
76 \%\end{array}$ \\
\hline Ordo & Ultisol & $\begin{array}{l}\text { Mempunyai nilai pH } 4.3- \\
5.6 \quad \text { (masam), yang } \\
\text { berbanding lurus dengan } \\
\text { KB , bila pH rendah KB } \\
\text { juga rendah }\end{array}$ & $\begin{array}{l}\text { Pada horison penciri Bt tanah } \\
\text { mempunyai horison } \\
\text { argilik/penimbunan liat dan } \\
\text { kejenuhan basa/KB BaCl2 TEA } \\
\text { pH } 8.2150 \mathrm{~cm}<35 \%\end{array}$ \\
\hline Subordo & Udult & $\begin{array}{l}\text { Berdasarkan pengamatan } \\
\text { profil tanah berada dalam } \\
\text { keadaan lembab (regim } \\
\text { kelembaban udik) }\end{array}$ & $\begin{array}{l}\text { Ultisol dengan regim kelembaban } \\
\text { tanah udik/lembab }\end{array}$ \\
\hline Great Grup & Hapludult & $\begin{array}{l}\text { Pada tingkat GG semua } \\
\text { kriteria masuk kedalam } \\
\text { Udult }\end{array}$ & $\begin{array}{l}\text { Pada tingkat GG semua kriteria } \\
\text { masuk kedalam Udult }\end{array}$ \\
\hline Subgrup & $\begin{array}{l}\text { Typic } \\
\text { Hapludult }\end{array}$ & $\begin{array}{l}\text { Pada tingkat SG Hapludult } \\
\text { yang lain }\end{array}$ & \\
\hline Famili & $\begin{array}{l}\text { Typic } \\
\text { Hapludult, } \\
\text { berliat, } \\
\text { campuran } \\
\text { isohiperterm } \\
\text { ik }\end{array}$ & $\begin{array}{l}\text { Typic Hapludult, yang } \\
\text { mempunyai kelas besar } \\
\text { butir berlempung, kelas } \\
\text { mineralogi campuran, dan } \\
\text { regim kelembaban iso } \\
\text { (selisih rata-rata suhu } \\
\text { kemarau dan hujan }<6 \% .\end{array}$ & $\begin{array}{l}\text { Typic Hapludult, kelas besar } \\
\text { butir berliat, kelas mineralogi } \\
\text { campuran (mineral liat illit tipe } \\
\text { 2:1 dan klorit tipe 2:1:1) didekati } \\
\text { dari KTK 6-23 me/100 g, } \\
\text { kelembaban iso (selisih rata-rata } \\
\text { suhu kemarau dan musim hujan } \\
<6 \%\end{array}$ \\
\hline
\end{tabular}


Berdasarkan uraian pada Tabel 5, maka jenis tanah di profil Glee Gapui Kecamatan Indara Jaya Kabupaten Pidie menurut Sistem Taksonomi Tanah USDA (Soil Survey Staff, 2006) termasuk ke dalam ordo Ultisol; subordo Udult; great group Hapludult; subgroup Typic Hapludult; dan family Typic Hapludult, berliat, campuran, isohipertermik.

\section{Kesimpulan}

\section{KESIMPULAN DAN SARAN}

1. Profil Gle Gapui penggal penentunya (horison $\mathrm{Bt}$ ) bertekstur liat dimana terjadi peningkatan liat sehingga termasuk kedalam horison argilik.

2. Nilai bobot isi berbanding terbalik dengan permeabilitas dan porositas

3. Reaksi tanah berbanding lurus dengan kejenuhan basa yaitu sama-sama rendah. Kandungan C- organik, P tersedia dan N total yaitu rendah. Kapasitas Tukar Kation yaitu sedang, asam-asam dapat ditukar $(\mathrm{H}$ dan $\mathrm{Al}$ ) yaitu tinggi.

4. Klasifikasi tanah Ultisol di lokasi profil Gle Gapui adalah Typic Hapludult, berliat, campuran, isohipertermik.

\section{Saran}

Tanah Ultisol didaerah penelitian mempunyai karakteristik baik morfologi, fisika dan kimia yang kurang baik yang menyebabkan kesuburan tanahnya juga rendah, sehingga tanahnya harus dikelola dengan cara pengapuran untuk menaikan $\mathrm{pH}$ tanah.

\section{DAFTAR PUSTAKA}

Buckman H.O dan N.C.Brady. 1982 Ilmu Tanah. Terjemahan Soegiman Bharata Aksara, Jakarta.

Hakim, N, M,Y Nyakpa, SA.M Lubis,Sg, Nugroho, M.R Saul, M,A Diha G,B Hong dan H.H Belly, 1986. Dasar-dasar Ilmu Tanah. Universitas lampung P:ress, Bandar Lampung.

Hardjowigeno,S.1993. Klasifikasi Tanah dan Pedogenesis, Akademi Preesindo. Jakarta
Hardjowigeno,S.2010. Ilmu Tanah,cetakan ke-7. Akademi Preesindo.Jakarta

Soil Survey Staff. 2006. Soil Taxonomy. $10^{\text {th }}$ Edition, USDA. Soil Conservation Service. Washington. 